enough to bring it to a temperature of $42^{\circ}$ to $46^{\circ} \mathrm{C}$. In bread made with yeast as well it is in accordance with the best bakery practice to increase the temperature toward the latter stages of the fermentation.

Sudden changes of temperature seem to have no marked influence upon the bacteria other than accelerating or retarding the rate of fermentation, for good bread was made from "emptyings" that had cooled to $22^{\circ}$, by making the sponge in the usual way at $39^{\circ} \mathrm{C}$. and the dough at $42^{\circ} \mathrm{C}$. This is of practical importance, for often in practice the "emptyings" are not kept at constant temperature. In the later stages, however, especially in the dough, it is essential that the temperature should be up to $40^{\circ} \mathrm{C}$. or over.

[To be continued in February.]

Department of IndUStrial Research, LNIVERSITY OF KANSAS, LAWRENCE.

\section{A RAPID METHOD FOR THE DETERMINATION OF SUL-} PHUR IN ROASTED BLENDE.

By C. C. Nitchie.

Received November 10, 1911.

As usually conducted, the sampling and analysis of the roasted ore drawn from a blende roasting kiln furnishes information useful only for purposes of record. A small portion is taken from each car load drawn and all such portions are mixed at the end of a day to make an average sample, which is analyzed on the following day.

This practice gives only average results, is of no value in determining the quality of ore from the individual draws, and fails entirely to detect the occasional car of poorly roasted ore which is transferred to the storage bins. It relies only on the judgment of the kiln men to determine when the ore is sufficiently roasted to be suitable for use in the spelter furnaces, and when it should be returned to the kiln for additional roasting.

In order to put the disposition of the ore on a definite basis, each draw should be sampled and analyzed for sulphur immediately after leaving the kiln. No ore should be placed in storage until the analysis is reported, showing that the sulphur is below a previously fixed maximum.

The usual gravimetric method of sulphur determination is unsuitable for such control analyses, on account of the time required, which would necessitate holding the ore in the car for a considerable length of time.

About a year ago Mr. M. F. Chase suggested to the writer that a rapid method, suitable for such determinations, might be devised by heating the ore sample in a current of air, absorbing the resulting oxides of sulphur in an excess of a standard alkali solution and titrating the excess. Based on this suggestion, the method to be described was worked up and has been in regular use since January, Ig I I.

In the kiln, the constituents of the original ore are mainly converted into oxides. Some remain partly in the original sulphide condition, while a small part of the zinc, some of the lead, and all of the lime are present as sulphates. On heating this ore in a current of air to a bright red, all of the sulphides are oxidized, giving the corresponding metallic oxides and sulphur dioxide with a little sulphur trioxide. The sulphates of zinc and lead are decomposed, giving zinc and lead oxides and sulphur trioxide. The calcium sulphate, however, is not easily decomposed by heat and remains unchanged, unless the temperature is raised to a point much higher than would be practicable in any roasting furnace. Strontium and barium would probably be present as sulphates. This has not been confirmed as none of the ores on which the method has been used have contained these elements.

At first thought, this property of the calcium sulphate might seem to be a drawback to the method, but, as the result wanted is an index of the completeness of the roast, and as, even under the best conditions at the kiln the calcium in the ore will always retain its equivalent in sulphur, no real error is introduced. The result obtained is the so-called "false sulphur," the sulphur which, under proper conditions, might have been removed from the ore in the kiln.

An unforeseen phenomenon is the evolution of copious fumes of zinc oxide as long as any sulphide remains unoxidized. This undoubtedly comes from the reduction of the zinc oxide and sulphate by the zinc sulphide (reactions analogous to the well known reactions in the smelting of lead sulphide ores) with volatilization of the zinc and subsequent oxidation by the air current.

$$
\begin{aligned}
& 2 \mathrm{ZnO}+\mathrm{ZnS}=3 \mathrm{Zn}+\mathrm{SO}_{2} \\
& \mathrm{ZnSO}_{4}+\mathrm{ZnS}=2 \mathrm{Zn}+2 \mathrm{SO}_{2} \\
& 2 \mathrm{Zn}+\mathrm{O}_{2}=2 \mathrm{ZnO}
\end{aligned}
$$

The cessation of this evolution of zinc oxide furnishes a very accurate indication of the completion of the decomposition of the sulphides and sulphates of the ore, and of the absorption of the sulphur oxides.

The fume is not appreciably dissolved by the alkali solution. Numerous tests after absorption have shown, at most, faint traces of zinc, not enough to affect the determination. To prove that it is zinc oxide, it was collected over distilled water in an inverted bottle which was then covered and allowed to stand until the fume had settled. It was then dissolved in a little dilute hydrochloric acid and potassium ferrocyanide solution added. This gave the white zinc ferrocyanide precipitate.

Phenolphthalein is used as the indicator in the titrations, as it is equally sensitive to sulphurous and sulphuric acid, showing neutrality with the normal salts of both.

For heating the ore sample to drive off the sulphur, nothing can be superior to the electric tube furnace, on account of its simple manipulation, accuracy of temperature control and cleanliness. The furnace which has been in use here is one similar to that described by Mr. G. M. Berry, ${ }^{\mathbf{}}$ with a fused silica combustion tube. It has given even better service than was claimed by $\mathrm{Mr}$. Berry, as the original winding was in service over 4,000 hours at $1000^{\circ} \mathrm{C}$.,

1 THIS JOURNAL, 2, 255. 
part of that time for about twelve hours a day, and for nearly four months continuously without a shut down.

The ends of the tube are cooled by wrapping with strips of cotton gauze which dip into distilled water.

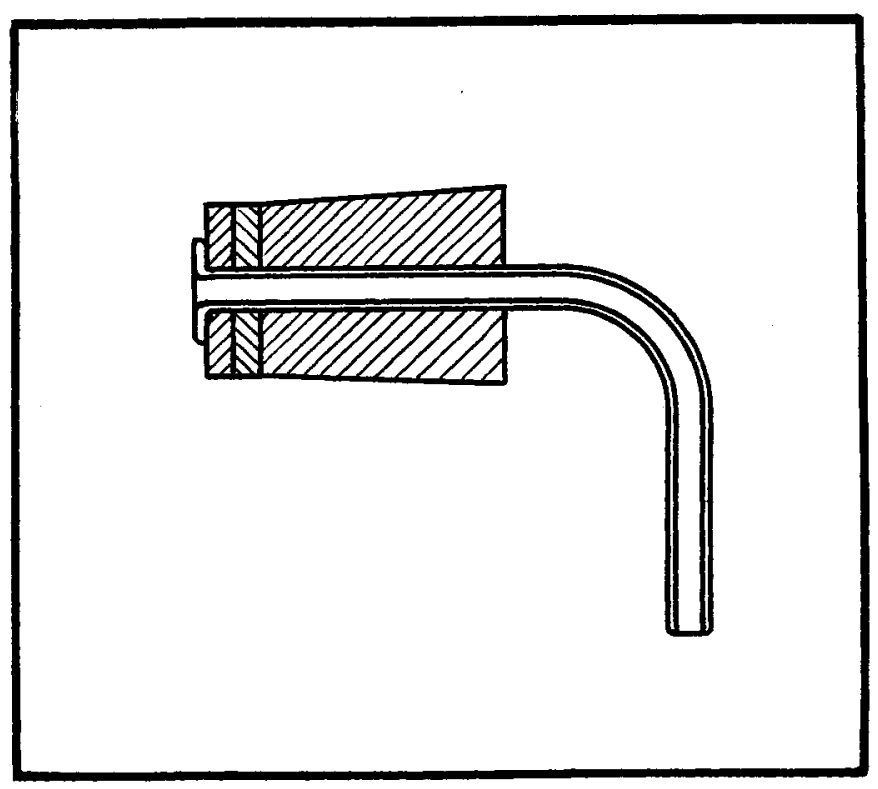

Fig. 1.

Tap water should not be used as it soon forms a crust of salts over the gauze, decreasing the cooling effect. An excellent reservir for the cooling water consists of a rectangular box of galvanized sheet iron of about the same length as the combustion tube, about six inches high and two inches wide. This is tightly closed except for two small openings, which communicate with laterally projecting troughs at the bottom near each end. This reservoir is filled with water and placed back of the furnace, with the small troughs under the ends of the combustion tube to receive the free ends of the gauze. Atmospheric pressure keeps the water from flowing into the troughs except when evaporation has lowered the water level to the top of the openings. This reservoir contains enough water to last a week or two. Even where the ends of the tube are water-cooled, there is danger that the rubber stoppers may be overheated by the radiant heat. To aroid this the ends of the stoppers are protected by discs of $1 / \mathrm{s}^{\prime \prime}$ asbestos board of the same diameter as the tube, held in place by bordering the ends of the small glass tubes as shown in Fig. I.

A convenient device for introducing the boat without the necessity of looking into the tube to make sure that the boat is not overturned is shown in Fig. 2. It is made of a piece of heavy wire, preferably of nickel or some other metal not easily corroded or rusted. One end is flattened out and so bent that the end projects over the end of the boat and in contact with it when both boat and wire are resting on the bottom of the combustion tube. The other end of the wire is bent at a right angle to make a hook for withdrawing the boat and also to indicate when the rod is in the proper position to keep the boat upright. A notch is filed around the wire or a finer wire wrapped around it as a guide at the point which is flush with the end of the tube when the boat has been pushed to the middle of the tube.

The solutions needed are an accurately standardized solution of sulphuric acid and one of equivalent strength of sodium hydroxide. A convenient solution is equivalent to 5 milligrams sulphur per cc. One cc. will then equal $0.5 \%$ sulphur on a I-gram sample. The two solutions should be as nearly equal as possible to avoid the necessity for corrections in reading one in terms of the other. There should be provided a reservoir of distilled water on an elevated shelf, with a siphon tube for use in diluting the contents of the absorption bulb to the proper volume, and for washing it out after the absorption.

The most convenient form of absorption vessel which we have found is the Murray potash bulb.

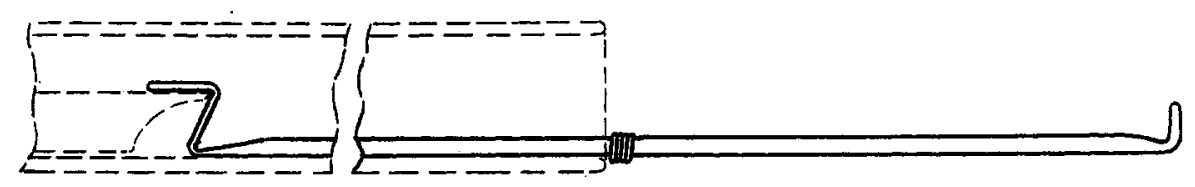

Fig. 2 .

The method as in use at present is as follows:

Each car, as it is brought from the kiln, is sampled in two places by a spear sampler. This sample is cut down with a riffle to about 50 grams and ground with a few turns of the muller in a Buck's mortar. 
Fine grinding is undesirable as it prolongs the time necessary for the analysis by restricting the free circulation of air through the ore. All that is necessary is to grind fine enough so that a one-gram sample will be fairly representative.

A measured quantity of the standard alkali solution is run into the absorption bulb. Seven to Io cc. will suffice in practically all cases. This is diluted with distilled water to a volume that will bring the solution into the fifth bulb when the air current is passing. The bulb is then attached by a bent glass tube to the exit end of the furnace.

One gram of the ore is placed in a combustion boat and introduced into the tube of the furnace which has already been heated to about $1000^{\circ} \mathrm{C}$. . A moderately rapid current of air, freed from carbon dioxide by caustic potash or soda lime, is passed through the apparatus until the sulphur is completely driven over into the alkali solution. This usually takes about six minutes. When the zinc oxide fume has completely disappeared from the large bulb of the absorption vessel, the air current is stopped. The absorption bulb is disconnected and the solution transferred to a beaker, the bulb being thoroughly rinsed out with distilled water. A few drops of phenolphthalein are added and the standard acid is run in until the solution is colorless. If the acid and alkali solutions are exactly equivalent, the volume of acid required is subtracted from the volume of alkali originally taken for the absorption. The difference is the volume of acid equivalent to the sulphur which has been burned out of the ore. If the solutions are of the concentration mentioned above, this volume is divided by 2 to give the per cent. of false sulphur in the ore.

When the acid and alkali solutions are not exactly equivalent, the value of I cc. of the alkali in terms of the acid solution must be determined. The volume of alkali taken for absorption is multiplied by this factor, giving the equivalent volume of the acid solution. The volume of acid used in the titration is then subtracted from this equivalent volume and the result divided by 2 to give the per cent. of false sulphur.

If total sulphur is wanted, it is only necessary to add to the false sulphur ${ }^{32} / 50$ of the per cent. of lime. With most ores the lime varies within comparatively narrow limits. It is usually sufficient for technical purposes to calculate, for a given grade of ore, the correction corresponding to the average per cent. of lime in that grade, and to add this correction to all determinations.

This method has been carefully checked up by running daily samples, both by the new method and by the gravimetric method. The accompanying table shows the results for twenty consecutive days on $W$ isconsin magnetic separator concentrates.

As a further check on the method, a number of ores were analyzed for (I) total sulphur by the gravimetric method, (2) lime, (3) false sulphur by the new method, and (4) fixed sulphur remaining in the ore

\begin{tabular}{|c|c|c|c|c|}
\hline $\begin{array}{c}\text { False sulphur } \\
\text { determined } \\
\text { by new method. } \\
\text { Per cent. }\end{array}$ & $\mathrm{CaO}$. & $\stackrel{\cdot}{\mathrm{CaO}} \times 32 / 56$ & $\begin{array}{l}\text { Total } \\
\text { sulphur } \\
\text { (calculated). }\end{array}$ & $\begin{array}{c}\text { Total } \\
\text { sulphur } \\
\text { (gravimetric). }\end{array}$ \\
\hline 0.6 & 3,4 & 1.9 & 2.5 & 2.8 \\
\hline 1.1 & 3.0 & 1.7 & 2.8 & 2.8 \\
\hline 1.1 & 3.1 & 1.8 & 2.9 & 2.9 \\
\hline 1.2 & 3.0 & 1.7 & 2.9 & 2.9 \\
\hline 0.9 & 3.3 & 1.9 & 2.8 & 2.8 \\
\hline 0.9 & 3.5 & 2.0 & 2.9 & 3.0 \\
\hline 1.2 & 3.1 & 1.8 & 3.0 & 2.8 \\
\hline 1.2 & 3.0 & 1.7 & 2.9 & 3.1 \\
\hline 1.0 & 3.0 & 1.7 & 2.7 & 2.7 \\
\hline 0.9 & 2.8 & 1.6 & 2.5 & 2.6 \\
\hline 1.0 & 2.8 & 1.6 & 2.6 & 2.9 \\
\hline 1.0 & 3.0 & 1.7 & 2.7 & 2.7 \\
\hline 1.1 & 3.0 & 1.7 & 2.8 & 2.8 \\
\hline 1.0 & 2.8 & 1.6 & 2.6 & 2.8 \\
\hline 1.1 & 2.8 & 1.6 & 2.7 & 2.9 \\
\hline 0.9 & 2.4 & 1.4 & 2.3 & 2.5 \\
\hline 1.2 & 2.8 & 1.6 & 2.8 & 2.5 \\
\hline 1.5 & 2.5 & 1.4 & 2.9 & 3.0 \\
\hline 0.9 & 3.0 & 1.7 & 2.6 & 2.6 \\
\hline 0.9 & 3.1 & 1.8 & $\quad 2.7$ & 2.8 \\
\hline & & Avera & ge, 2.73 & 2.80 \\
\hline
\end{tabular}

after the volatilization of the false sulphur. The results are given in the following table:

$\begin{array}{cccccc}\begin{array}{c}\text { Total S } \\ \text { (gravimetric). }\end{array} & \text { CaO. } & \begin{array}{c}\text { CaO } \times \\ 32 / 56 .\end{array} & \begin{array}{c}\text { Fixed S } \\ \text { (gravi- } \\ \text { metric) }\end{array} & \begin{array}{c}\text { False S } \\ \text { (new } \\ \text { method). }\end{array} & \begin{array}{c}\text { Total S (sum } \\ \text { of false and } \\ \text { fixed sulphur) }\end{array} \\ 2.3 & 3.0 & 1.7 & 1.6 & 0.7 & 2.3 \\ 2.3 & 3.0 & 1.7 & 1.8 & 0.6 & 2.4 \\ 5.9 & 0.9 & 0.5 & 0.5 & 5.5 & 6.0 \\ 2.5 & 0.6 & 0.3 & 0.4 & 2.2 & 2.6\end{array}$

These figures show that, under the prescribed con ditions, the fixed sulphur calculated from the per cent. of lime is the same as that found by analysis, and that the total sulphur calculated from the false and fixed sulphur is the same as that determined by analysis.

Attempts to use the method for the determination of sulphur in raw ores have led to low results, either from failure to absorb the larger quantities of sulphur gases or from condensation of part of the sulphur trioxide in the cooled portions of the tube. As there is not the same demand for a rapid method in the case of raw ores as in that of the roasted, these attempts have not been continued.

There is every reason to believe that a similar method could be applied to the determination of sulphur in other roasted ores besides those of zinc, for example, pyrites cinders, copper ores, etc., where the sulphides and sulphates are easily decomposed by air and heat.

\section{CONCLUSIONS.}

I. The method is very rapid, less than ten minutes being required from taking the sample to completing the titration and calculation.

2. The results are sufficiently accurate for control work in the operation of the plant.

3. The operations are all so simple that they may be entrusted to boys with but little training in chemical manipulation.

DEPUF, ILL. 